Mahreen Mahmud
Nawazish Mirza $^{2}$

UDK336.761(549.1 Karachi)

Preliminary paper

Prethodno priopćenje

\title{
VOLATILITY DYNAMICS IN AN EMERGING ECONOMY: CASE OF KARACHI STOCK EXCHANGE
}

\begin{abstract}
The paper aims to model and forecast the volatility in the stocks traded at the Karachi Stock Exchange before and during the recent financial crisis using the GARCH, EGARCH and GJR-GARCH models. We find the stock return volatility to be characterized by clustering and displaying asymmetries. Results point to the capability of the EGARCH(1,1) model at forecasting for both periods lending support to the use of GARCH family of models for emerging markets during crisis. We find evidence for a synthetically constructed index based on trading volume capturing the volatility structure of the market as well as that based on market capitalization which has important implications for investors.
\end{abstract}

Keywords:Karachi Stock Exchange, Trading Volume, Forecasting, Volatility Clustering

JEL Classifications: G12 G17

\section{INTRODUCTION}

Financial markets play a dominant role in economic development by facilitating savings and promoting investments. Most of the developing economies experience slow and stagnant progression that emanates from their weak, fragile and highly volatile financial markets. Market panics and frictions are recurring characteristics that result from increased volatility making these markets vulnerable to crashes. Therefore, extreme volatility could ultimately distort financial system by negatively impacting the economic performance. The crashes in a highly volatile market could impair investors' confidence driving out consumer spending. Similarly, market makers with superior information can exploit volatility to yield abnormal returns on expense of small uninformed investors. Lastly, an increase in stock market volatility is interpreted as an increase in market risk resulting in an augmented cost of capital. This could impose severe capital constraints for small firms and affect financing policies. This makes analysis of volatility critical for investors, regulators and businesses.

The traditional measure of stock market volatility refers to the standard deviation of returns. The recent empirical evidences have reported some caveats for this estimate. Standard deviation is a valid estimate of volatility if the underlying returns or log prices are stationary and follow a Gaussian distribution. However, if these returns are not independent and identically distributed the standard deviation is not a convincing measure of volatility. This warrants for analysis of higher order moments in stock prices to capture the volatility and its variations over time. Mandelbrot (1963) [1] was the first to observe the incidence of volatility clustering in financial markets. The volatility clustering is the tendency that large variations

1(Corresponding Author) Research and Teaching Fellow, Centre for Research in Economics and Business, Lahore School of Economics, Intersection Phase VI and Burki Road, Lahore, Pakistan. mahreenm@gmail.com

2 Associate Professor, Finance. Centre for Research in Economics and Business, Lahore School of Economics, Intersection Phase VI and Burki Road, Lahore, Pakistan. nawazish@lahoreschool.edu.pk 
will be followed by large variations and small variations are followed by small variations. This phenomenon is likely to be persistent, non stationary and volatility is expected to be mean reverting rather than remaining constant over time. Engle (1982) [2] and Bollerslev (1986) [3] proposed a new class of Autoregressive Conditional Heteroscedasticity (ARCH) models to explain the behavior of time varying volatility clustering. The empirical research on these models demonstrated superior results in favor of ARCH class models both for modeling historic volatility and forecasting (Taylor, 2004 [4]; Corradi and Awartani, 2005 [5]). The impact of volatility is even severe in emerging markets that lack structural and informational inefficiencies. The research on these markets has reported presence and persistence of volatility shocks contributing towards high risk for these economies. This makes variance or standard deviation a biased estimate of volatilities for these markets and warrants the use of ARCH class models for understanding volatility structure (Kim and Singal, 1997 [6]).

The infrequent trading a common trait of emerging markets, has severe implications for empirical estimations. The volatility behavior in a stock market is analyzed by the volatility patterns of stock indices; however, if these indices contain sleeping stocks and index values rely on few high volume stocks, the resulting estimates of volatility will be seriously biased. Therefore, unlike developed economies, use of stock indices from emerging markets with non synchronous trading could produce anomalous findings. This study aims to provide robust results by complimenting traditional market indices by a synthetic trading volume index.

Karachi Stock Exchange (KSE) is the leading and most liquid stock market of Pakistan that has witnessed severe volatility shocks in last five years. This has resulted in increased risk to market participants. The volatility could distort economic system and in economies like Pakistan, where stock market just began to develop in last decade, the consequences of volatility could be extreme. Therefore, it is vital to study the dynamics of volatility in KSE notably in last five years where market activity was substantially higher since the inception of the exchange. This study would attempt to model the higher order moments of volatility using the ARCH class models. More importantly, these models are also used for forecasting volatility; therefore, we will provide an insight about the prediction power of these models using an out of sample approach before and during the recent crisis.

This paper is expected to have multiple contributions towards existing academic literature. First, this would be the most comprehensive study of volatility dynamics in KSE as it compares the maximum number of ARCH class models for modeling historic volatility visà-vis previous researches on Pakistan. Secondly, we also provide evidence on forecasting ability of these models that has never been reported before for KSE. Thirdly, no prior study in Pakistan has incorporated the impact of trading volume on volatility and almost all studies have investigated the volatility using a market capitalization based index of KSE-100. Some of the companies in KSE-100 index are subject to non synchronous trading that could bias the estimates. Therefore, we construct a synthetic index based on trading volumes (top ten) to provide robust estimates for our research. Lastly, the sample period is unique as it incorporates both bullish and bearish trends with high level of trading volumes as compared to previous researches where trading activity was moderate to low.

The rest of the paper is as follows: Section II will present a brief review of literature; Section III will explain the data used, methodology of the research in section IV followed by results in section V and concluding comments in VI. 


\section{LITERATURE REVIEW}

Most of the early research concentrated on developed countries stock markets. Research on the topic has now expanded to emerging markets where similar methodology is applied to model the volatility. However, the analysis at large has concentrated on the symmetric GARCH models. Non-constant volatility has been a common result in all studies while the evidence has been mixed once again with respect to the superiority of a specific model (see Gokcan, 2000 [7]; Shin, 2005 [8]).

Considerable work has been done to study the dynamics of the KSE since the 90s at large and to study the volatility displayed by the stock prices in particular. The authorities have made considerable efforts to regulate the market in order to control the pronounced volatility that is the characteristic of KSE. Uppal and Mangla (2006) [9] analyzed the impact of regulations and found that the difference in the volatility between the two periods is statistically insignificant pointing to the inability of the measures taken to curb the volatile trend of the market. They attributed the failure to the monopoly position of the KSE and the lack of accountability mechanism in the regulations pursued by the SECP.

Hameed and Ashraf (2006) [10] also find that the reforms of SECP have been relatively unsuccessful. Mubarik and Javaid (2009) [11] verifies empirically that there is significant interaction between trading volume and return volatility when volume is entered into variance equation of GARCH-M model (see also Mustafa and Nishat, 2008 [12]). All these studies provide evidence of volatility persistence and clustering to be present in the KSE. They also make attempts to factor into their modeling the non-constant nature of the volatility. While an attempt is made by Kiani (2006) [13] to factor in the presence of leverage effects in the stock return series in the Pakistani case, this has not been followed by application of any formal check to test for the presence of such effects. Hence, the efforts of modeling the volatility in the case of studies on Pakistan is limited to the use of symmetric GARCH models. Further, no attempt has been made to follow up the modeling stage with the forecasting of volatility. As has been detailed above, a reliable estimate of future volatility is of key importance to the development of sophisticated financial instruments in the country. It is at this end that this study attempts to make its greatest contribution to the existing literature.

\section{DATA}

The aim of the study is to evaluate the volatility patterns displayed by the daily stock returns in the KSE for 2004 to 2009 period. This sample period consists of 1439 daily observations for the 6 year trading period. The motivation is to evaluate the degree of persistence displayed by the returns over time. In order to adequately capture the volatility displayed by the market, there is a need for a representative index for the market. An obvious choice is the KSE-100 index which is a value weighted index of the stocks of 100 leading companies traded in the KSE based on their market capitalization and is a leading indicator of the Pakistan's equity market. Two series will be used ${ }^{3}-$ one the adjusted closing prices $\left(\mathrm{I}_{\mathrm{ct}}\right)$ and other constructed from the average of the highest and lowest value of the index for the day $\left(\mathrm{I}_{\mathrm{hlt}}\right)$. In addition, to capture adequately the price movements in the market at large the KSE All Share Index ${ }^{4}\left(\mathrm{I}_{\text {alt }}\right)$ will also be employed.

Furthermore, an index will be constructed which will not be based on market capitalization unlike the other two but rather on trading volume. Ten companies with the

\footnotetext{
${ }^{3}$ Data Source: Yahoo Finance

${ }^{4}$ Data Source: KSE website
} 
highest trading volume will be selected semi-annually for the sample period ${ }^{5}$. The daily stock prices of these companies will be used to construct an index weighted on the value of market capitalization of these ten companies. The purpose is to study the volatility patterns displayed by the most highly traded stocks at the KSE. This index will be re-balanced semi-annually to accommodate any changes in patterns of trading over time ${ }^{6}$. The base value of the index at $1^{\text {st }}$ January 2004 is set at 1000 for ease of comparison so that all indices being used for analysis have a common basis. For each subsequent day the index is:

$$
I_{\text {ot }}=(\text { Total market Capitalization } t / \text { Base period Value }) * 1000
$$

where $t$ is the period from $2^{\text {nd }}$ January 2004 to $31^{\text {st }}$ December 2009 and Base period value is the total market capitalization of the 10 most highly traded companies for the period as on $1^{\text {st }}$ January 2004.

Analysis across this wide range of indices will allow identification of the model that is best able to capture the impact of shocks on the market returns. The second part will be an evaluation of the predictive ability of the fitted models. This will be carried out by out of sample forecast evaluation. No study has been found that evaluates the predictive ability of the GARCH family of models for Pakistan. This exercise is particularly pertinent in the recessionary times we are in today as such periods are characterized by pronounced volatility.

The analysis will be first done over the entire sample period and then extended to a sub-period. Volatility will be modeled over the 2004-2008 period with the year 2009 used for out of sample forecast evaluation. Next the in-sample period extending from $1^{\text {st }}$ January 2004 to $31^{\text {st }}$ December 2007 which consists of 951 daily observations for the 3 year trading period with the year 2008 will be used for out of sample forecast. The sample period is chosen so that volatility during relatively stable period can be modeled and forecasting into a time frame that includes the impact of the world recession being felt on the KSE can be done. Trading showed such bullish trends that the index was fixed during parts of the last quarter of 2008.

The the daily stock index values of $I_{t}\left\{I_{o t}, I_{a l}, I_{h l t}, I_{a c t}\right\}$ series are non stationary; they shows no trend and does not revert back to their mean. There is consesus in finance literature on employing the Dickey Fuller (DF) test to ascertain the stationarity of the series to be studied $^{7}$. This formally tests the presence of a unit root which is an indicator of non stationarity of the series being tested.Regressing the first difference of all four $I_{t}$ series does not allow us to reject the null hypothesis at $1 \%$ levels of confidence which confirms that the series is non-stationary. Due to the non-stationary nature of the $\left(\mathrm{I}_{\mathrm{t}}\right)$ series the daily stock returns ${ }^{8}\left(R_{1} t\right)$ will be used for analysis. Coverting the index value series yields stationary series as confirmed by the DF test and $R_{t}\left\{R_{c t}, R_{o t}, R_{a l t}, R_{h l t}\right\}$ series can now be used for analysis (Results of Dickey Fuller tests in appendix 1).

The mean for all series is close to 0 and the return series are characterized by thicker tails than normal (summary statistics in Table 1 and series plots with normal curve imposed in appendix II). The normal curve is characterized by 0 skewness and kurtosis of 3 . Our sample series have all a negative value for skewness and excess kurtosis (kurtosis value exceeding 3) pointing to their distrubutions being negatively skewed and more peaked than the normal

\footnotetext{
${ }^{5}$ Data Source: Business Recorder Online

${ }^{6}$ This is for consistency purposes as the KSE 100 index is also re-balanced semi-annually

${ }^{7}$ See Enders (2004),

${ }_{8} R_{t}=\ln \left(\frac{I_{t}}{I_{t-1}}\right)$
} 
curve $^{9}$. Furthermore the series also demonstrates another common characteristic of financial time series - volatility clustering i.e. periods of well defined high and low volatility.

Table: 1 Summary statistics for $\mathrm{R}_{\mathrm{t}}$ series

\begin{tabular}{cccccccc}
\hline & $\begin{array}{c}\text { Number of } \\
\text { observations* }\end{array}$ & Mean & $\begin{array}{c}\text { Std. } \\
\text { Dev. }\end{array}$ & Min & Max & $\begin{array}{c}\text { Skewnes } \\
\text { s }\end{array}$ & Kurtosis \\
\hline $\mathrm{R}_{\mathrm{hlt}}$ & 1387 & 0.0005 & 0.015 & -0.084 & 0.120 & -0.439 & 8.61 \\
$\mathrm{Rct}$ & 1387 & 0.0005 & 0.016 & -0.086 & 0.090 & -0.535 & 5.48 \\
$\mathrm{R}_{\mathrm{alt}}$ & 1387 & 0.0006 & 0.016 & -0.200 & 0.090 & -0.658 & 7.39 \\
$\mathrm{R}_{\mathrm{ot}}$ & 1376 & 0.0004 & 0.020 & -0.070 & 0.070 & -0.245 & 4.27 \\
\hline
\end{tabular}

Note: Observations for the period in 2008 when KSE remained closed have been excluded

Source: Author's own calculations

\section{METHODOLOGY \\ MODELING VOLATILITY}

As first step the volatility of the four indices daily returns over the sample periods will be modeled in order to make predictions about future. As a second step, all fitted models will be employed to make forecasts into the future. All analysis has been done using Eviews Software. The first hypothesis of interest is to test whether the returns at KSE display time varying volatility returns.

To formally check for the presence of such ARCH effects the Lagrange Multiplier (LM) test of Engle (1982) [2] is applied. The expectation a-priori is that the errors will display nonconstant variance and will hence render the commonly used Ordinary Least Squares technique as invalid. This will necessitate the use of a model which has been developed especially to take this non-constant variance into account. Such a model is the specification as proposed by Bollerslev (1986) [3] is:

$\boldsymbol{h}_{t}=\alpha_{0}+\sum_{i=1}^{q} \alpha_{i} \varepsilon_{t-i}^{2}+\sum_{i=1}^{p} \beta_{i} \boldsymbol{h}_{t-i}$

Where there are p lags of conditional variance and q lags of squares of shocks in previous periods. The impact of volatility clustering is incorporated by including lags of the dependent variable. This allow for the values in previous periods to impact the value of volatility today. GARCH process does not differentiate between the impact of a positive and negative unexpected change in returns. It is therefore unable to capture asymmetric effect of good and bad news on the volatility of the financial time series - a phenomenon termed as "leverage effect”.

Anderson et al. (2001) [14] present two explanations for leverage effect. One is that when there is a negative shock (i.e. a negative return) it increases financial and operating leverage which causes the volatility to rise. The second is that "if the market risk premium is an increasing function of volatility, large negative returns increase the future volatility by more than positive returns due to a volatility feedback effect”. This means that the effect on

\footnotetext{
${ }^{9}$ The joint skewness/kurtosis test for normaility yields a p value of 0.00 , allowing the null of normality to be rejected for all
} series. 
volatility of unexpected bad news in the market would be higher than from that of unexpected good news of the same magnitude. To test for leverage effects, the sign bias test of Engle and $\mathrm{Ng}$ (1993) [15] is employed. The presence of asymmetry in financial time series necessitates the use of variants of GARCH which modifies the GARCH specification (1) to capture this phenomenon. The mixed response on the superiority of a particular kind of model does not allow the choice of one type of asymmetric model and so the popular EGARCH and GJRGARCH are estimated. It is important to note here that the work done on modeling volatility in Pakistan has been limited to the use of symmetric models and even though presence of leverage effects was tested for by Kiani (2006) [13], asymmetric models have not been employed on Pakistan to formally account for it.

A form of the Threshold-GARCH model is the GRJ-GARCH model proposed by Golsten et.al (1993) [16]:

$\boldsymbol{h}_{t}=\alpha_{0}+\sum_{i=1}^{q} \alpha_{i} \varepsilon_{t-i}^{2}+\gamma_{1} \varepsilon_{t-1}^{z} I_{t}+\sum_{i=1}^{p} \beta_{i} h_{t-1}$

Where the leverage effect is captured by the use of the dummy variable $I_{t}$, such that $I_{t}=1$ if $\varepsilon_{\mathrm{t}}$ ${ }_{1}<0$ (bad news), $I_{t}=0$ otherwise. The specification is exactly the same as the GARCH(p,q), augmented by the term with the dummy variable to capture the asymmetry.

EGARCH(p,q) proposed by Nelson (1991) [17] also captures the asymmetries by employing a logarithmic specification thereby ensuring that the conditional variance is positive and that there is no need to impose non-negativity constraints. It is different from GJR-GARCH since it makes use of standardized residuals and ensures that conditional variance is determined both by the sign and magnitude of these.

$\log \left(h_{t}\right)=\alpha_{0}+\sum_{i=1}^{p} \beta_{i} \log \left(h_{t-1}\right)+\sum_{i=1}^{q} \llbracket \alpha_{i}\left(\left|\frac{\varepsilon_{t-i}}{\sqrt{h_{t-i}}}\right| \bar{\eta}\right)+\sum_{i=1}^{q}\left[\gamma_{i}\left(\frac{\varepsilon_{t-i}}{\sqrt{h_{t-i}}} \rrbracket\right)\right.$

If $\gamma_{\mathrm{i}}$ is significantly negative then there is asymmetric effect since the effect of negative shock $\left(\alpha_{1} i-\gamma_{1} i\right)$ will be greater than that of a positive shock $\left(\alpha_{1} i+\gamma_{1} i\right)$ of the same magnitude. Enders (2004) [18] note that EGARCH has the advantage that its coefficients can be negative as the $h_{t}$ is obtained after taking anti-log and so can never be negative.

Equations (1) - (3) are first fitted in their most parsimonious form with lags $p=q=1$. Once the equations have been estimated, the next step would be to check if they adequately fit the data using the Portmanteau test to check for autocorrelation of errors. Autocorrelation in the errors from the estimated equations will indicate that the models have not fit the data thereby necessitating the inclusion of additional lags. Once we have an adequate fit as indicated by no autocorrelation in the errors, the next step is to forecast using the estimated models. In order to select the best model, forecasts from each model will be evaluated on the criterions detailed below. An alternative method to this would be to select the best model based on information criterions such as Akaike's and Bayesian which would indicate the best in-sample fit. However, the aim of this study is not to select the specification that best models the volatility in sample but rather to select the one which makes the best forecasts out of sample. Therefore concentration will be on the out of sample predicating capability of the models fitted and not on their in sample fit. 


\section{OUT OF SAMPLE FORECAST EVALUATION}

For the purposes of forecast evaluation, one step ahead forecasts for the out of sample periods are made. Once the model has been estimated, in making each forecast the actual data available till that point is used as inputs into the equation estimated for conditional volatility by that model. The quality of these will be evaluated using standard forecast evaluation technique of employing loss based functions. In order to evaluate the quality, a measure for the actual realized volatility is needed. However, volatility is a latent variable that is unobserved and develops stochastically over time. Squared returns $\left(\mathbf{r}_{\mathbf{t}}^{2}\right)$ are therefore commonly used as a proxy for the true volatility (the mean of the return series is 0 ). The simplest way to evaluate how different the conditional variance predictions made by the model are from the proxy being used for the true variance is to calculate the mean forecast error (ME):

$M E=\left(\frac{1}{m}\right) \sum_{t=1}^{m}\left(\left[\hat{y}_{t}-y_{t}\right)\right]^{m}$

Where m represents the number of forecasting observations and $\hat{y}_{t}$ is the predicted volatility while $y_{t}$. More sophisticated statistics have been developed like a common forecast evaluation statistic, the Mean square error (MSE):

$M S E=\left(\frac{1}{m}\right)\left[\sum_{t=1}^{m}\left(\hat{y}_{t}-y_{t}\right)^{2}\right]$

MSE squares the forecast errors $\left(\hat{y}_{t+h}-y_{t+h}\right)$ and so penalizes larger errors more than smaller ones.

The DM test of Diebold and Mariano (1995) [19] is a test for comparing the forecasting ability of two models. This test will be employed to evaluate if there is any statistical difference between the forecasts from the models in the two sub period, before and after the crisis. To employ the test, $\operatorname{var}(\bar{d})$ is required. If $d_{i}$ series is uncorrelated then $\operatorname{var}(\bar{d})$ is given by: $\frac{\gamma_{0}}{H-1}$ else specification given by Enders (2004) is followed: $\operatorname{var}(\bar{d})=$ $\frac{\gamma_{0}+2 \gamma_{1}+\cdots+2 \gamma_{q}}{H-1}$ are significant and $\mathrm{H}$ is the number of forecast errors.

\section{EMPIRICAL RESULTS}

\section{MODELING THE CONDITIONAL VOLATILITY}

Lagrange Multiplier (LM) Test allows us to conclude that there are ARCH disturbances in the all the returns series. Parameter estimates of equations (1) - (3) across all indices are reported in table $2^{10}$. Using the Portmanteau test on the errors from the models does not allow the null hypothesis of autocorrelations being insignificant to be rejected and the conclusion to be drawn that volatility has been correctly modeled. Results for $\operatorname{GARCH}(1,1)$ show that the coefficient of the lag of conditional variance $\beta_{1}$ is low which indicates that the effects of past is less persistent than for developed market. However, it is still high enough to indicate that the impact is more persistent than pronounced (since $\left.\alpha_{1}<\beta_{1}\right)$.

\footnotetext{
${ }^{10} \mathrm{ARCH}$ LM Test on squared residuals from the fitted models show that they are correctly specified and able to model the serial correlation structure
} 
Employing formal tests, the series were found to be display pronounced conditional variance in the face of a negative shock. The next two models fitted formally account for this asymmetric effect in addition to the phenomena of volatility clustering and excess kurtosis. For the GJR-GARCH $(1,1)$, the coefficient on the indicator function $\gamma_{1}$ is significant and positive for all series which shows that there are asymmetric effects. Also, for the EGARCH(1,1) model the $\gamma_{1}$ for all series turn to be negative and significant, once again verifying the presence of asymmetric effects.

\section{FORECAST EVALUATION}

For out of sample forecast evaluation, one-step ahead forecasts from each of the three models is made. Loss function evaluation technique is employed on these forecasts with the $\mathbf{r}_{\mathbf{t}}^{2}$ of each series acting as the benchmark (results in table 3). The lower the value of the criterions estimated using forecasts from a model, the better the forecasts from the model.

The low values for ME points to the supremacy of the asymmetric models in the case of all series. The MSE gives a mixed indication with EGARCH, the superior model in two out of the four series while the GARCH models do slightly better in the other two $\left(R_{\text {alt }}, R_{\text {act }}\right.$.) at predicting volatility. A particularly interesting result is how well the synthetically constructed series of the top 10 traded stocks is able to model and forecast the volatility in the market. Both ME and MSE point towards the superiority of the EGARCH(1,1) model in predicting volatility of the $R_{o t}$. As a next step, it is worthwhile to check for the robustness of the constructed $\mathrm{R}_{\mathrm{ot}}$ series on different time periods. As a point of comparison the $\mathrm{R}_{\mathrm{ht}}$ series will be estimated using the EGARCH model as both ME and MSE point to its supremacy in this case. 


\begin{tabular}{|c|c|c|c|}
\hline$\frac{3}{4}$ & 3 & & \\
\hline 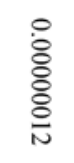 & 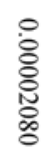 & 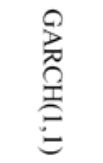 & \\
\hline 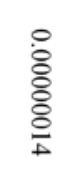 & 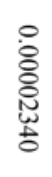 & 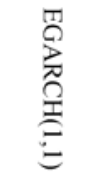 & 줔 \\
\hline $\begin{array}{l}\circ \\
\stackrel{\circ}{\circ} \\
\stackrel{\circ}{u}\end{array}$ & 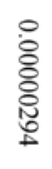 & 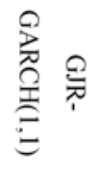 & \\
\hline 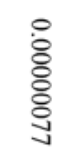 & 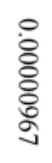 & 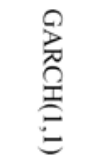 & \\
\hline 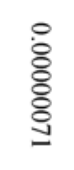 & 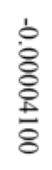 & 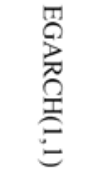 & 곀 \\
\hline
\end{tabular}

\begin{tabular}{|c|c|c|c|c|c|c|}
\hline $\begin{array}{l}\mathscr{D} \\
0 \\
\vdots\end{array}$ & $\vec{F}$ & $B$ & $\Phi$ & 2 & & \\
\hline 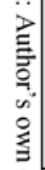 & & $\begin{array}{l}\text { o. } \\
\text { 悹 } \\
\text { 今. } \\
\text { 总 }\end{array}$ & 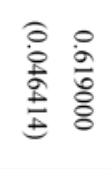 & 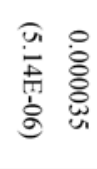 & 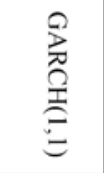 & \\
\hline 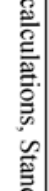 & 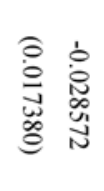 & 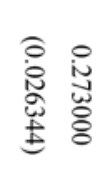 & 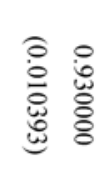 & 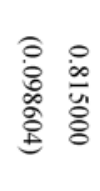 & 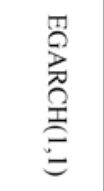 & 줔 \\
\hline 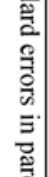 & 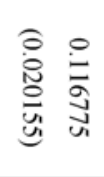 & 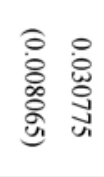 & 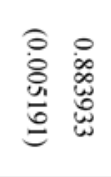 & 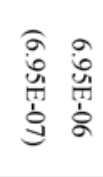 & 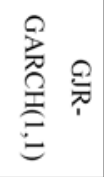 & \\
\hline 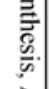 & & $\stackrel{\circ}{\stackrel{\circ}{b}}$ & Oे & తิ & $\sum_{\overparen{\Omega}}^{0}$ & \\
\hline
\end{tabular}

\begin{tabular}{|c|c|c|}
\hline 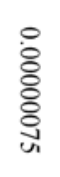 & 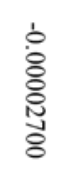 & 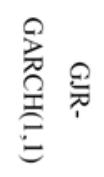 \\
\hline $\begin{array}{l}\circ \\
\stackrel{8}{0} \\
\stackrel{\circ}{0} \\
\text { u. }\end{array}$ & $\begin{array}{l}0 \\
\frac{0}{0} \\
\frac{0}{4} \\
\frac{1}{0}\end{array}$ & 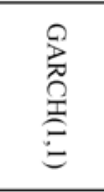 \\
\hline 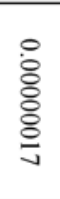 & 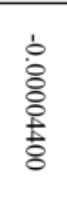 & 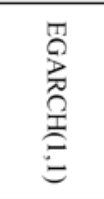 \\
\hline $\begin{array}{l}\circ \\
\text { ळे } \\
\stackrel{\circ}{\infty}\end{array}$ & 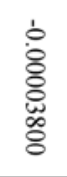 & 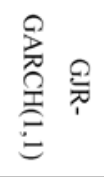 \\
\hline 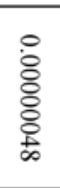 & 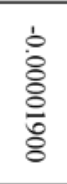 & 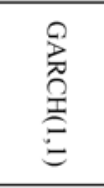 \\
\hline 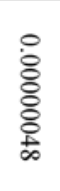 & 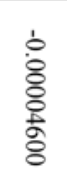 & 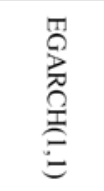 \\
\hline 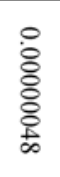 & 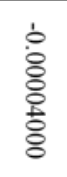 & 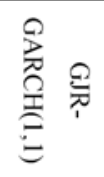 \\
\hline
\end{tabular}

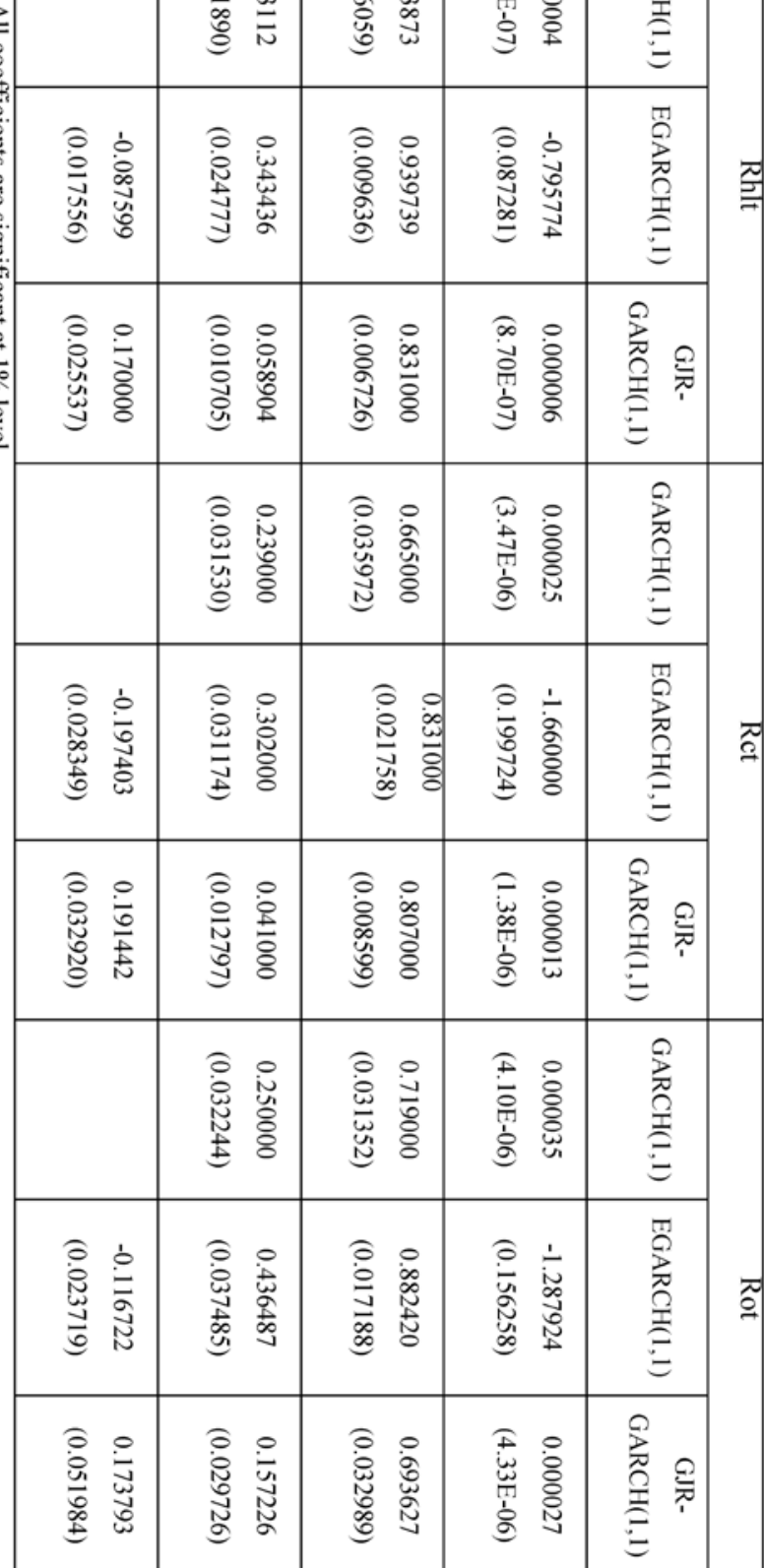


The purpose of this exercise is twofold. First is to test the model in different periods of relative tranquility and volatility in the stock market in order to evaluate is the predicting capability of the series is not hampered. Second, it is of interest to see if the $R_{0 t}$ series continues to be as good a representative of the actual market fluctuations as the $\mathrm{R}_{\mathrm{hlt}}$. This process will entail reducing the sample period from ending in December 2008 to ending in December 2007 and estimating the chosen model, the EGARCH on this sample with the year 2008 as the out of sample period.

One-step ahead forecasts for the year are made from this model so that comparisons can be made with the out of sample forecasts that were made for the entire period including the crisis that hit KSE. In this stable period the model when applied to both series yields quite similar results, lending support to the synthetically constructed index's ability to capture the volatility in the KSE (see table 4). The forecasting ability also indicates that the volatility is well predicted by the model.

Table: 4 Results from EGARCH(1,1) estimation for the 2004-07 sample period

\begin{tabular}{ccc}
\hline & $\mathrm{R}_{\mathrm{ot}}$ & $\mathrm{R}_{\mathrm{hlt}}$ \\
\hline$\alpha_{0}$ & -1.123 & -0.883 \\
& $(0.133)$ & $(0.173)$ \\
$\beta_{1}$ & 0.898 & 0.933 \\
& $(0.014)$ & $(0.018)$ \\
$\alpha_{1}$ & 0.394 & 0.367 \\
& $(0.035)$ & $(0.048)$ \\
$\gamma_{\mathbf{1}}$ & -0.089 & -0.102 \\
ations, Standard errors in parenthesis, All coefficients are significant at the $1 \%$ level
\end{tabular}

By mid 2008 the worldwide crisis had begun to show its impact in the stock market of the country with the KSE 100 index starting to decline. Hence, it is interesting to evaluate how the model is able to perform for the in the sample period from 2007 till 2008 with 2009 acting as out of sample period. As expected the forecast evaluation shows that the value for all evaluation criterions at all horizons have increased as compared to 2007 (results in table 5). This signals worsened forecasting, a result which is not surprising given that crisis periods are more volatile than usual and so predicting becomes more difficult. However, the DM test signals no statistical difference between the forecasting ability of the model - equally capable in making volatility predictions during crisis period as it is in making them during normal times. The increased volatility which is a characteristic of crisis period is adequately accounted for by the model. An important contribution is that the model fitted takes special account of the leverage

Table: 5 Results from EGARCH(1,1) forecast for 2008 period

\begin{tabular}{lcc}
\hline & $\mathrm{R}_{\mathrm{ot}}$ & $\mathrm{R}_{\mathrm{hlt}}$ \\
\hline $\mathrm{ME}$ & 0.0003 & 0.0001 \\
MSE & $6.123 \mathrm{E}-06$ & $5.487 \mathrm{E}-07$ \\
\hline Source: Author's own calculations & &
\end{tabular}




\section{CONCLUSION}

These results have interesting implications for understanding the dynamics of volatility in an emerging stock market. Volatility of returns in financial markets is critical in attracting both local and foreign investments particularly in small economies with limited potential for diversification. Investors align their return expectations according to the risk preferences and this warrants precision in quantification of relevant risk. The traditional measure of risk using standard deviation of returns is flawed in small economies for at least two reasons. First, standard deviation could proxy risk if the distribution of returns is normal and second, if the volatility is constant over time.

The emerging markets have imperfections owing to weak regulatory framework, domination by few market makers, asymmetric information, speculative trading and volume concentration in few selected stocks. Therefore, the volatility is likely to cluster with skewed and extreme tail distribution of returns and this require analysis of higher moments. Our results demonstrate that in Pakistan, the volatility clustering is evident and risk can be adequately modeled using GARCH class of models. The results remained robust with out of sample forecast evaluation. The implications for financial decisions are immense. For capital budgeting purposes, if volatility clustering is ignored and reliance remains on standard deviation, the cost of capital will be imprecise with low estimates during periods of high volatility and high estimates in periods of low volatility. In valuation decisions, standard deviation will require a constant risk premium while in presence of volatility clustering, utility maximizing investors should demand a high premium in times of augmented risk level.

Another important finding is the ability of trading volume based synthetic index to capture and forecast volatility. This is consistent with the general notion of investment behavior in emerging markets. Investors in such markets have either low access to fundamental information or they do not have substantial capacity to properly analyze and interpret available information and therefore most of participants (even if they are speculators) would use trend of stock index as a critical base to their investing decisions. Our evidence suggests that trading volume index could better reveal the volatility dynamics in emerging markets.

The financial sector is even more sensitive to appropriate quantification of volatility to manage their exposures. The Basle II (2001) introduced measures of value at risk and default likely indicator based on information extracted from the stock market mainly volatility of asset returns. Therefore, if the volatility is modeled assuming a normal distribution where actual returns are fat tailed or skewed with persistent shocks, the estimation error of volatility could result in misleading exposures with dire consequences. Similarly, if policy makers are expected to introduce financial derivatives, the pricing of such instruments should incorporate the clustered volatility of underlying asset returns and not the Gaussian based standard deviation estimate. 


\section{REFERENCES}

Andersen, Torben G, Tim Bollerslev, Francis X. Diebold and Heiko Ebens 2001). “The Distribution of Stock Return Volatility” Journal of Financial Economics, 61 pp. 43-76.

Bollerslev, Tim. (1986). "Generalized autoregressive conditional hetroskedasticity"." Journal of Econometrics, 31(3): 307-327.

Corradi, Valentina, and Basel M. A. Awartani.(2005) "Predicting the volatility of the S\&P500 stock index via GARCH models: the role of asymmetries.” International Journal of Forecasting 21: 167-183.

Diebold, Francis X and Roberto S. Mariano. (1995). "Comparing Predictive Accuracy". Journal of Business and Economic Statistics, 13: 253-265. Enders, Walter. (2004). Applied Econometrics Time Series. 2nd ed. John Wiley \& Sons,. Print. Engle, Robert F. (1982). "Autoregressive Conditional Heteroscedasticity with Estimates of the Variance of United Kingdom Inflation”." Econometrica,50 (4): 987-1007.

Engle, Robert F, and Victor K. Ng. (1993). "Measuring and Testing the Impact of News on Volatility.” Journal of Finance, 48 (5): 1749-1778.

Glosten, Lawrence R, Ravi Jagannathan and David E. Runkle. (1993) “On the relation between the expected value and the volatility of the nominal excess return on stocks". Journal of Finance, 48 (5): 1779-1801.

Gokcan, S. (2000) Forecasting Volatility of Emerging Stock Markets: Linear versus Nonlinear GARCH Models, Journal of Forecasting, 19: 499 - 504

Hameed, Abid and Ashraf, Hammad. (2006)."Stock Market Volatility and Weak-form Efficiency: Evidence from an Emerging Market” The Pakistan Development Review 45 (4): 1029-1040

Kiani, Khurshid M., (2006). "Predictability in Stock Returns in an Emerging Market:Evidence from KSE 100 Stock Price Index”. The Pakistan Development Review,45 (3): 369-381

Kim, E.H. and V. Singal. (1997). "Opening up of Stock Markets: Lessons from Emerging Economies” Virginia Tech. Working Paper.

Mandelbrot, Benoit B. (1963) “The variation of certain speculative prices”, Journal of Business, 36: 394

Mustafa, K. \& Nishat, M., (2008). "Trading Volume and Serial Correlation in Stock Returns in Pakistan”, Philippine Review of Economics 45.2

Mubarik, Fauzia and Javaid, Attiya Y. (2009). "Relationship between stock return, trading volume and volatility: evidence from Pakistani stock market. Asia Pacific Journal of Finance and Banking Research 3.3.

Nelson, Daniel B. (1991). "Conditional Heteroskedasticity in Asset Returns: A New Approach”. Econometrica, 59 (2): 347-370.

Shin, Jaeun. (2005). “Stock Returns and Volatility in Emerging Stock Markets” International Journal of Business and Economics 4 (1): 31-43.

Taylor, James W. (2004) "Threshold Volatility forecasting with smooth transition exponential smoothing.” International Journal of Forecasting, 20: 237-286.

Uppal, Jamshed Y., and Mangla, Inayat U. (2006). "Regulatory Response to Market Volatility and Manipulation: A Case Study of Mumbai and Karachi Stock Exchanges”. The Lahore Journal of Economics, 11 (2): 79-105. 
Appendix I: Dickey Fuller Test Results

\begin{tabular}{ccccc}
\hline & OT & ALT & CT & HLT \\
\hline $\mathrm{I}_{\mathrm{t}}$ & -1.561 & -1.669 & -1.664 & -1.644 \\
$\mathrm{R}_{\mathrm{t}}$ & -33.779 & -32.595 & -32.596 & -28.386 \\
\hline
\end{tabular}

$1 \%$ Critical Value $=-3.430$

Appendix II: Plot of $\mathbf{R}_{\mathbf{t}}$ series

(a) $\mathrm{R}_{\mathrm{alt}}$

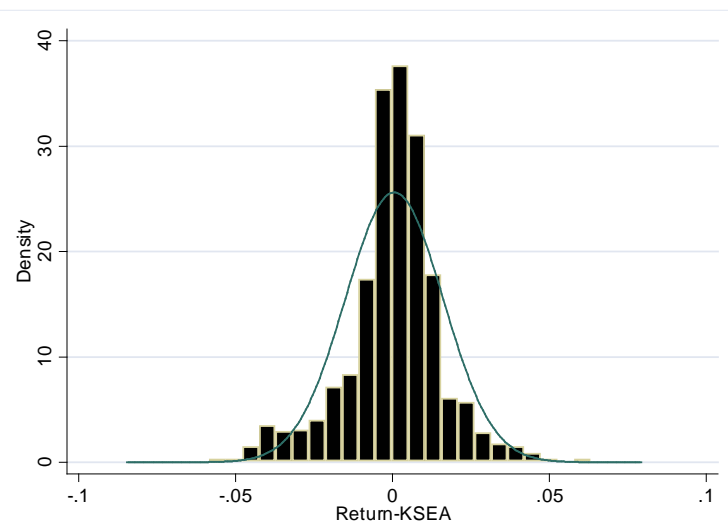

(c) $\mathrm{R}_{\mathrm{ct}}$

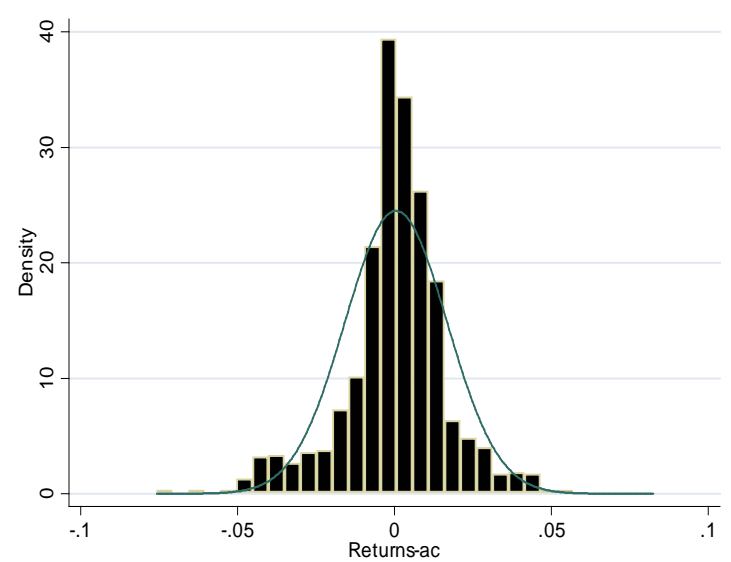

(b) $\mathrm{R}_{\mathrm{ot}}$

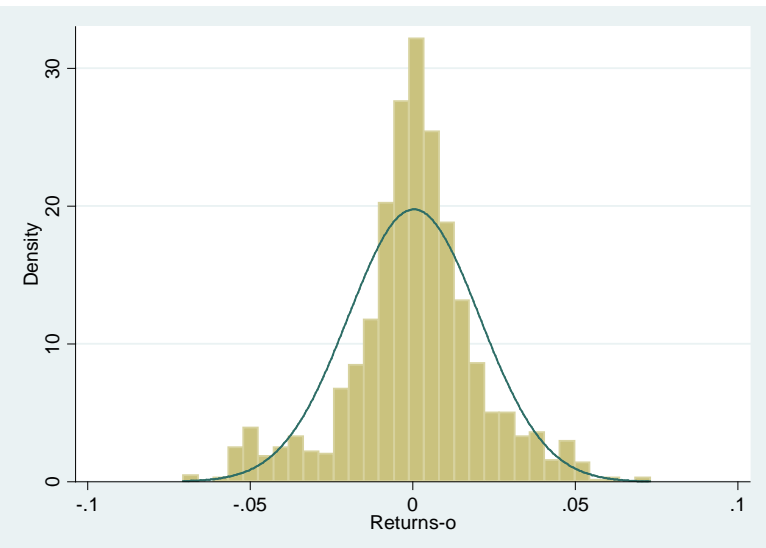

(d) $\mathrm{R}_{\text {hlt }}$

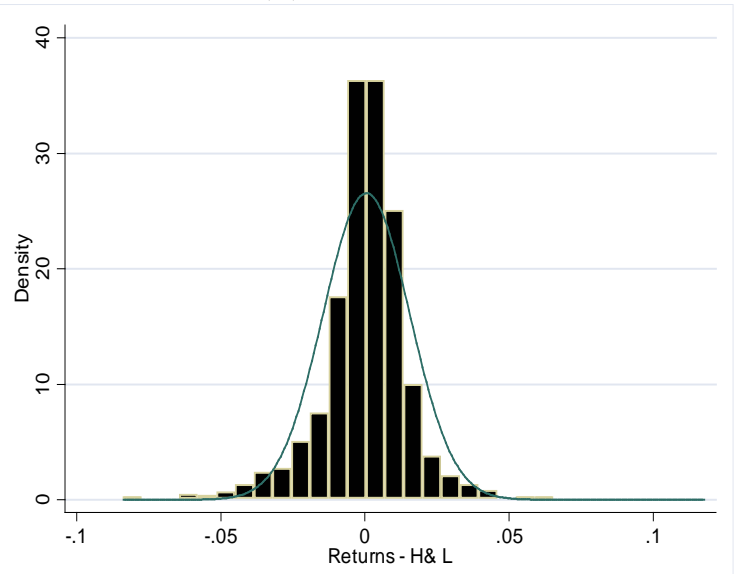




\section{DINAMIKA VOLATILNOSTI U NOVIJIM GOSPODARSTVIMA:}

\section{SLUČAJ BURZE U KARACHIJU}

\section{SAŽETAK}

Rad ima za cilj stvoriti model i predvidjeti volatilnost dionica kojima se trgovalo na burzi u Karachiju prije $i$ za vrijeme nedavne financijske krize koristeći GARCH, EGARCH $i$ GJR-GARCH modele. Zaključujemo da je volatilnost zarade na burzi obilježena klasteringom te pokazuje asimetrije. Rezultati ukazuju na sposobnost EGARCH(1,1) modela da predviđa za oba perioda potvrđujući korisnost GARCH grupe modela za tržišta u nastajanju u vrijeme krize. Ima dokaza sintetički stvorenog indeksa na bazi volumena trgovine koji hvata volatilnost strukture tržišta, kao i onog baziranog na tržišnoj kapitalizaciji što ima važne implikacije za investitore.

Ključne riječi: burza u Karachiju, volumen trgovine, predviđanje, klastering volatilnosti

JEL klasifikacija: G12 G17 